\title{
VIBRATION ANALYSIS OF LINE CONTINUUM WITH NEW MATRICES OF ELASTIC AND INERTIA STIFFNESS
}

\author{
J.C. Ezeh ${ }^{1}$, O.M. Ibearugbulem ${ }^{2}$, C.N. Okoli ${ }^{3}$ \\ ${ }^{l}$ Civil Engineering Department, Federal University of Technology, Owerri, Nigeria \\ ${ }^{2}$ Civil Engineering Department, Federal University of Technology, Owerri, Nigeria \\ ${ }^{3}$ Civil Engineering Department, Federal University of Technology, Owerri, Nigeria
}

\begin{abstract}
Vibration analysis of line continuum with new matrices of elastic and inertia stiffness is introduced in this research. The matrices were developed using Ritz method and assumed six term Taylor's series shape function. Two deformable nodes were introduced at the centre and at the ends of line continuum which brings the number of deformable node to six. The six term Taylor's series shape function assumed was substituted into strain energy equation and into inertia work (Kinetic energy) equation. Their resulting functional were minimized, resulting in $6 \times 6$ elastic stiffness matrix and $6 \times 6$ inertia stiffness matrix respectively, for vibration analysis. The two matrices were employed, as well as the traditional $4 \times 4$ matrices in classical free vibration analysis of four line continua with different boundary condition. The results from the new $6 x 6$ matrices of elastic and inertia stiffness were very close to exact results, with average percentage difference of $0.212425421 \%$ from exact solution. Whereas those from the traditional $4 \times 4$ matrices and $5 \times 5$ matrices differed from exact results with average percentage difference of $14.72352281 \%$ and $0.275 \%$ respectively. Thus the newly developed $6 \times 6$ matrices of elastic and inertia stiffness are suitable for classical free vibration analysis of line continua
\end{abstract}

Keywords: $6 x 6$ stiffness system; vibration; inertia; line continuum; variational principle; deformable node; shape function; classical; numerical; analysis; beam

\section{INTRODUCTION}

The increase demand for taller structures with high-energy sources (generator), free of foundation vibration and cross winds etc, which create intense vibration excitation problems requires careful analysis and design to avoid resonance or an undesirable dynamic performance. However, the classical approach to line continuum, to obtain exact result, requires formulating the governing differential equation and obtaining the analytical solution. As Moon-Young et al. (2003) pointed out, this analytical method, however, is sometimes inefficient because analytical operations in solving a system of simultaneous ordinary differential equations with many variables maybe too complex. Also Bhavikatti S.S. (2005) pointed out that if structure consists of more than one material, it is difficult to use classical method, but finite element can be used without any difficulty. Moreover, as observed by Ibearugbulem et al (2013), the traditional $4 \times 4$ stiffness matrix and its load vector cannot classically analyze flexural line continua except using them numerically (more than one element in one analysis). This difficulty in using the traditional $4 \times 4$ classical approach is evident in the work of Iyengar (1988), Chopra (1995) and Yoo and Lee (2011). Ibearugbulem et al (2013) developed 5 x 5 stiffness matrices capable of classically analyzing stability and dynamic line continuum by introducing one degree of freedom at the mid span of line continuum, but some of their solutions are not exact solution. This research work will generate new $6 \times 6$ stiffness matrices for vibration analysis of line continuum by introducing two degrees of freedom (rotation and deflection) at the mid span and at the ends of line continuum which brings the number of deformable node to six. The six term Taylor's series shape function assumed was substituted into strain energy equation and into inertia work (Kinetic energy) equation. Their resulting functional were minimized, resulting in $6 \times 6$ elastic stiffness matrix and $6 \times 6$ inertia stiffness matrix respectively, for classical free vibration analysis.

\section{GOVERNING EQUATION}

The line continuum governing equation is:

$$
\begin{aligned}
& \frac{d^{4} w}{d x^{4}}-\frac{M \omega^{2} w}{E I} \\
& =0
\end{aligned}
$$

The assumed six term Taylor's series shape function

$$
\begin{aligned}
\mathrm{w}(\mathrm{x})=\mathrm{a}_{0}+\mathrm{a}_{1} \mathrm{x} & +\mathrm{a}_{2} \mathrm{x}^{2}+\mathrm{a}_{3} \mathrm{x}^{3}+\mathrm{a}_{4} \mathrm{x}^{4} \\
& +\mathrm{a}_{5} \mathrm{x}^{5}
\end{aligned}
$$




\section{ENERGY VARIATIONAL PRINCIPLE}

From Naschie (1990), strain energy is given as:

$$
\mathrm{U}_{\mathrm{s}}=\frac{\mathrm{EI}}{2} \int_{0}^{\mathrm{L}}\left(\mathrm{W}^{\prime \prime}\right)^{2} \mathrm{dx}
$$

Work performed by Inertia (kinetic energy)

$$
\mathrm{U}_{\mathrm{m}}=\frac{-\mathrm{M} \omega^{2}}{2} \int_{0}^{\mathrm{L}}\left(\mathrm{W}^{\prime}\right)^{2} \mathrm{dx}
$$

\section{NEW STIFFNESS MATRICES FOR}

\section{CLASSICAL FREE VIBRATION}

The new stiffness matrices for classical free vibration of line continuum are presented by considering deformable node at the centre, and ends of line continuum (each node with two degrees of freedom) to bring the number of deformable nodes to six. The resultant deformable nodes and corresponding forces as illustrated in figure 1 are:

$$
\begin{aligned}
& \text { [Nodes }]=\left[\begin{array}{llll}
W_{1} \theta_{1} & W_{2} \theta_{2} & W_{3} \theta_{3}
\end{array}\right] \\
& {[\mathrm{FEA}]=\left[\begin{array}{llllll}
\mathrm{QF}_{1} & \mathrm{MF}_{1} & \mathrm{QF}_{2} & \mathrm{MF}_{2} & \mathrm{QF}_{3} & \mathrm{MF}_{3}
\end{array}\right]}
\end{aligned}
$$

Where [FEA] is Fixed End Action

[Nodes] means deformable nodes

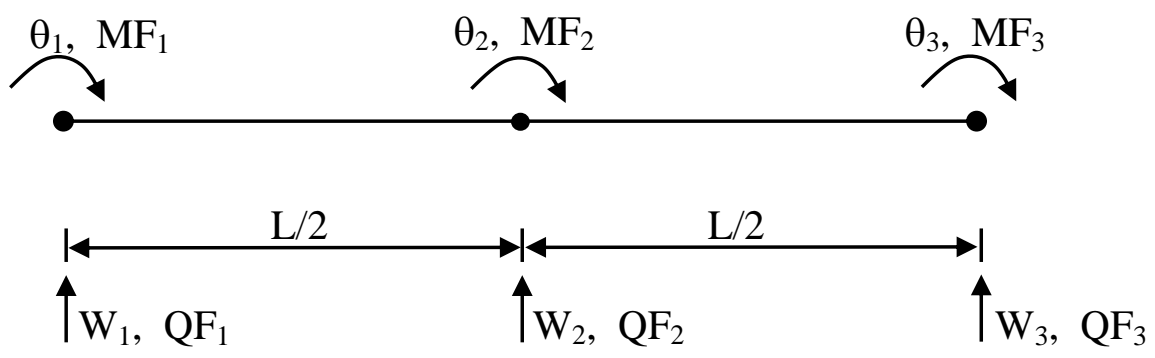

Fig 1: Six - deformable nodal system of 6 x 6 stiffness system

Substituting equation (2) into equations (3) and (4) and minimizing them in variational principle results in equation (7) and (8) respectively:

$$
\begin{aligned}
\frac{\mathrm{du}}{\mathrm{d} \Delta} & =[\mathrm{k}] \cdot[\Delta] \\
\frac{\mathrm{du}}{\mathrm{d} \Delta} & =\left[\mathrm{k}_{\mathrm{I}}\right] \cdot[\Delta]
\end{aligned}
$$

$$
\mathrm{K} . \mathrm{E}=\frac{\mathrm{EI}}{\mathrm{L}^{3}} *\left[\begin{array}{cccccc}
145.4857143 & 32.51428571 \mathrm{~L} & -102.4 & 54.85714286 \mathrm{~L} & -43.08571429 & 6.914285714 \mathrm{~L} \\
32.51428571 \mathrm{~L} & 9.485714286 \mathrm{~L}^{2} & -25.6 \mathrm{~L} & 9.142857143 \mathrm{~L} & -6.914285714 \mathrm{~L} & 1.085714286 \mathrm{~L}^{2} \\
-102.4 & -25.6 \mathrm{~L} & 204.8 & -4.55 \mathrm{E}-13 \mathrm{~L} & -102.4 & 25.6 \mathrm{~L} \\
54.85714286 \mathrm{~L} & 9.142857143 \mathrm{~L}^{2} & 0 \mathrm{~L} & 36.57142857 \mathrm{~L} & 54.85714286 \mathrm{~L} & 9.142857143 \mathrm{~L} \\
-43.08571429 & -6.914285714 \mathrm{~L} & -102.4 & 54.85714286 \mathrm{~L} & 145.4857143 & -32.51428571 \mathrm{~L} \\
6.914285714 \mathrm{~L} & 1.085714286 \mathrm{~L}^{2} & 25.6 \mathrm{~L} & 9.142857143 \mathrm{~L} & -32.51428571 \mathrm{~L} & 9.485714286 \mathrm{~L}^{2}
\end{array}\right]
$$

Where $\Delta$ is the nodal deformation vector expressed in equation (9)

$$
[\Delta]^{\mathrm{T}}=\left[\begin{array}{lll}
\mathrm{W}_{1} \theta_{1} & \mathrm{~W}_{2} \theta_{2} & \mathrm{~W}_{3} \theta_{3}
\end{array}\right]
$$

$\mathrm{K}$ and $\mathrm{KI}$ are the required new $6 \times 6$ matrices of elastic and inertia stiffness for classical free vibration analysis of line continuum as shown in equation (10) and (11) respectively. 


$$
\begin{aligned}
& \text { [K. E }]_{\mathrm{I}} \\
& =\omega^{2} \mathrm{ML} \\
& {\left[\begin{array}{cccccc}
0.150937951 & 0.008225108 \mathrm{~L} & 0.063492063 & -0.011544012 \mathrm{~L} & 0.018903319 & -0.002092352 \mathrm{~L} \\
0.008225108 \mathrm{~L} & 0.000577201 \mathrm{~L}^{2} & 0.006349206 \mathrm{~L} & -0.000865801 \mathrm{~L}^{2} & 0.002092352 \mathrm{~L} & -0.00021645 \mathrm{~L}^{2} \\
0.063492063 & 0.006349206 \mathrm{~L} & 0.406349206 & 1.43219 \mathrm{E}-14 \mathrm{~L} & 0.063492063 & -0.006349206 \mathrm{~L} \\
-0.011544012 \mathrm{~L} & -0.000865801 \mathrm{~L}^{2} & 3.55271 \mathrm{E}-15 \mathrm{~L} & 0.009235209 \mathrm{~L}^{2} & 0.011544012 \mathrm{~L} & -0.000865801 \mathrm{~L}^{2} \\
0.018903319 & 0.002092352 \mathrm{~L} & 0.063492063 & 0.011544012 \mathrm{~L} & 0.150937951 & -0.008225108 \mathrm{~L} \\
-0.002092352 \mathrm{~L} & -0.00021645 \mathrm{~L}^{2} & -0.006349206 \mathrm{~L} & -0.000865801 \mathrm{~L}^{2} & -0.008225108 \mathrm{~L} & 0.000577201 \mathrm{~L}^{2}
\end{array}\right]}
\end{aligned}
$$

\section{RESULTS AND DISCUSSIONS}

The natural frequency were determined from classical analysis of line continuum using: $4 \times 4,5 \times 5$, and $6 \times 6$ stiffness matrices (elastic and inertia stiffness). The comparison of these data with the exact natural frequencies for the four different boundary conditions are presented in table 1 . It is observed from table 1, that the comparison of the data from the conventional $4 \times 4$ system and the exact solution shows that the traditional $4 \times 4$ differ very much from the exact solution, excepts for cantilever $(\mathrm{C}-\mathrm{F})$ beam. The percentage difference of $32.94422872 \%$ and $10.94224924 \%$ for propped cantilever $(\mathrm{C}-\mathrm{R})$ beam and simply supported $(\mathrm{P}-\mathrm{R})$ beam; and the average percentage difference of $14.72352281 \%$ of the $4 \times 4$ stiffness system are very high to be ignored. It was not possible for classical analysis of clamped $(\mathrm{C}-\mathrm{C})$ beam with the traditional $4 \times 4$ stiffness system. Also, the comparison of the data from the present study and classical exact solution shows that the result from this present study are very close to exact result. The highest percentage difference of $0.36 \%$ for clamped $(\mathrm{C}-\mathrm{C})$ beam was recorded. The average percentage difference of $0.212425421 \%$ between the 6 x 6 stiffness matrix system and exact results are minimal and quite acceptable. The results from 5 x 5 matrix system (Ibearugbulem et al 2013) showed better closeness to exact solution than the $4 \times 4$ system. However, the results from the present $6 \times 6$ system are better than those of $5 \times 5$ system. These outcome implies that the result from the present study is more close to exact solution than that of Ibearugbulem et al. Hence, the newly developed stiffness matrices are suitable for classical free vibration analysis of line continuum.

Table 1: Fundamental Natural Frequency, $\omega\left(\sqrt{\frac{\mathrm{EI}}{\mathrm{ML}^{4}}}\right)$ From Classical Analysis

\begin{tabular}{|l|l|l|l|l|l|l|l|}
\hline $\begin{array}{l}\text { Continua } \\
\text { Boundary } \\
\text { Conditions }\end{array}$ & $\begin{array}{l}\text { Exact } \\
\text { Result } \\
(\omega)\end{array}$ & $\begin{array}{l}\text { Result } \\
\text { From 4x4 } \\
\text { Stiffness } \\
\text { System }(\omega)\end{array}$ & $\begin{array}{l}\text { Percentage } \\
\text { Difference with } \\
\text { Exact Result }\end{array}$ & $\begin{array}{l}\text { Result from } \\
\text { 5x5 Stifness } \\
\text { System }(\omega)\end{array}$ & $\begin{array}{l}\text { Percentage } \\
\text { Difference } \\
\text { with Exact } \\
\text { Result }\end{array}$ & $\begin{array}{l}\text { Result from } \\
\text { 6x6 Stiffness } \\
\text { System }(\omega)\end{array}$ & $\begin{array}{l}\text { Percentage } \\
\text { Difference } \\
\text { with } \\
\text { Result }\end{array}$ \\
\hline Exact
\end{tabular}

\section{REFERENCES}

[1] Beard, C.F. (1996). Structural Vibration Analysis and Damping. Butterworth - Heinemann, Jordan Hill Burlkington London. Pp. 133 - 137.
[2] Bhavikatti (2005). Finite Element Analysis. New Age International (P) Limited, Publishers. Daryaganj, New Delhi - 110002 .

[3] Chopra, A.K. (1995). Dynamic of Structures: Theory and Applications to Earthquake. New Jersey: Prentice Hall Inc. 
[4] Ibearugbulem, O.M., Ettu, L.O. and Ezeh, J.C. (2013). A New Stiffness Matrix for Analysis of Flexural Line Continuum. The International Journal of Engineering and Science, 2(2).

[5] Ibearugbulem, O.M., Ettu, L.O., Ezeh, J.C. and Anya, U.C. (2013). A New Stiffness Matrices for Stability and Dynamic Analysis of Line Continuum. The International Journal of Engineering Research and Development, Vol. 6.

[6] Iyengar, N.G.R. (1988). Structural Stability of Columns and Plates. New York: John Wiley \& Sons.

[7] Moon - Young, K., Nam 11, K. \& Hee - Tack, Y. (2003). Exact Dynamic and Static Stiffness Matrices of Shear Deformable Thin-walled Beam - Columns. Journal of Sound and Vibration, Vol. 267, No. 1, Pp. $29-55$

[8] Naschie, M.S.E. (1990). Stress, Stability and Chaos in Structural Engineering: An Energy Approach. London McGraw - Hill Book Company.

[9] Yoo, C.H., and Lee C.S. (2011). Stability of Structures: Principles and Applications, Oxford. 